\title{
Review of variable leading-edge patents for aircraft wings and engine inlets and their relevance for variable pitot inlets in future supersonic transport
}

\author{
S. Kazula ${ }^{1}$ (D) K. Höschler ${ }^{1}$
}

Received: 7 December 2020 / Revised: 17 May 2021 / Accepted: 24 May 2021 / Published online: 12 June 2021

(c) The Author(s) 2021

\begin{abstract}
The motivation for designing variable pitot inlets for future supersonic transport (SST) is explained. A comprehensive overview of existing technological solutions for variable leading edges of aircraft wings and engine inlets is given. The advantages and limitations of over 80 solutions, as well as their relevance for application on variable pitot inlets for SST are described. The challenges of existing solution options concerning design methodologies, level of detail, and experience with a technology are identified.
\end{abstract}

Keywords Overview of variable inlet lips $\cdot$ Variable aero engine inlet $\cdot$ Morphing nacelle intake $\cdot$ SST

\section{Introduction}

Mitigating the global climate change and its consequences should be one of the primary goals of mankind. In aviation, climate protection is supported by the ACARE-goals (Advisory Council for Research and Innovation in Europe) of the European Union for 2020 [1] and 2050 [2]. These goals include the reduction of $\mathrm{CO}_{2}$-emissions. This reduction can be achieved by improving the aircraft engines and their integration. Improved engine integration can reduce the aerodynamic drag of the aircraft and the propulsion efficiency of the system. This drag reduction has positive effects in terms of required thrust, achievable range, as well as fuel consumption, and hence, its produced $\mathrm{CO}_{2}$-emissions.

The optimisation of the air flow around the engine inlet presents a way to reduce the aircraft drag. The inlet ensures the generation of thrust by supplying the required air mass flow to the engine. In subsonic aviation, this is mainly achieved by nearly annular, rigid pitot inlets. However, rigid inlets can only accomplish a trade-off concerning safety and aerodynamic drag, and thus, propulsive efficiency within the

S. Kazula

stefan.kazula@gmx.de

Chair of Aero Engine Design, Brandenburg University of Technology, Siemens Halske-Ring 14, 03046 Cottbus, Germany highly diverse operation conditions. This trade-off can be mitigated by variable inlets, which have been investigated in a number of studies [3-5]. Nevertheless, subsonic variable inlets are currently not in use, as their aerodynamic benefits are outweighed by their limitations concerning complexity, reliability, and costs. Variable pitot inlets for SST applications up to Mach 1.6 offer higher aerodynamic benefits, which could compensate for these limitations [6]. Furthermore, variable pitot inlets have several advantages compared to other supersonic inlet types in terms of uniformity, length, and weight, while their increased complexity remains a challenge.

This paper supports the design of variable pitot inlets by identifying suitable solution principles and technologies. First, the trade-off in the design of pitot inlets and the potential benefits of variable inlets are introduced. Subsequently, existing technological solutions for variable leading edges of aircraft wings and engine inlets are identified and described regarding their functionality, complexity, and relevance for application on variable pitot inlets for SST.

\section{Aero-engine inlets}

The thrust generated by the engines enables the aircraft to fly. Thereby, the inlet ensures the thrust generation by supplying the required air mass flow to the engine. This air flow must be provided with high uniformity under all operating 
conditions, high-pressure recovery and limited to a maximum velocity of Mach 0.6 [7]. The fulfilment of this task is primarily determined by the geometry of the inlet.

Current commercial aircraft is operated exclusively under subsonic conditions. Applications in this range of flight speeds use approximately annular pitot inlets with a rigid geometry [8]. Such a rigid geometry can only provide a trade-off for the diverging aerodynamic requirements during the flight mission. During aircraft take-off and climb, flow disturbances due to the angle of attack and crosswind can occur. As a result, flow separations can occur in the area of the inlet. The inlet geometry must prevent these flow separations and potentially resulting in dangerous events [9]. For this purpose, a rounded, relatively thick geometry is utilised [10], see Fig. 1, top left. Conversely, during cruise flight, the emphasis is on minimising aerodynamic drag. Thus, a

\section{Take-off and climb conditions}

Blunt lip

Thin lip

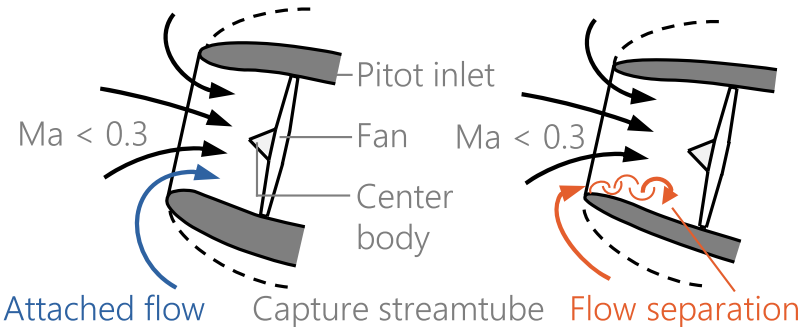

\section{Subsonic cruise flight}

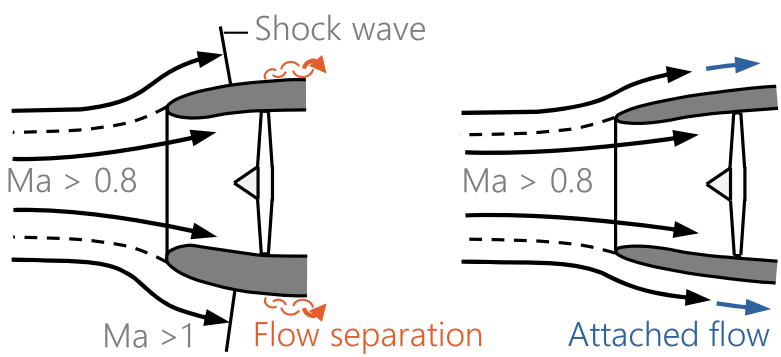

\section{Supersonic cruise flight}

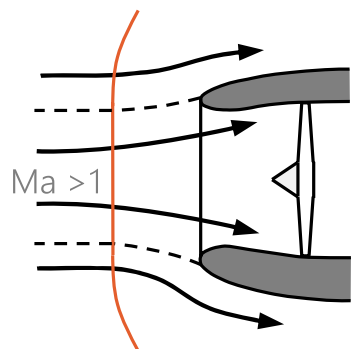

Detached shock wave

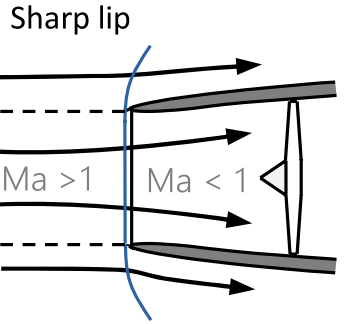

Attached shock wave
Fig. 1 Comparison of pitot inlet geometries relatively thin geometry is required in the subsonic cruise regime [10], see Fig. 1, middle right. Moreover, there are also non-commercial supersonic applications that use pitot inlets [9]. The geometry of pitot inlets for these supersonic applications is as sharp and thin as possible to generate minimal drag [11], see Fig. 1, bottom right.

The identification of the ideal geometry of rigid pitot inlets is the subject of numerous studies [12-15]. However, designing the inlet with a variable geometry offers many advantages, compare chapter 2.2 in detail. On one hand, by means of a variable design, an inlet geometry that is resilient to hazardous flow separations can be set during take-off and climb operation. On the other hand, a geometry with reduced drag can be implemented during cruise flight conditions. This drag reduction results in potential range benefits of up to $5 \%$ for solely subsonic applications and up to $30 \%$ for supersonic applications with flight speeds up to Mach 1.6 $[16,17]$.

\subsection{Variable pitot inlets}

The geometry of pitot inlets can be adjusted in different regions of the inlet with diverse aerodynamic effects. The variation of the following geometric inlet parameters is reasonable for the respective flight conditions:

- the curvature of the inlet lip,

- the cross-sectional areas at inlet entry and throat level,

- the lengths of inlet lip, diffuser, and nacelle forebody, as well as

- the curvature of the nacelle forebody [16], compare Fig. 2.

Boundary layer control offers a further option for variable inlets. Hereby, the geometric inlet contour remains unchanged, while flow separation is avoided, e.g., by means of tangential blowing into the boundary layer or by air suction. Also, blow-in doors, auxiliary intake doors, or bleed doors have been utilised in earlier applications.

Due to their considerable potential benefits, variable inlets have been investigated in previous studies, compare

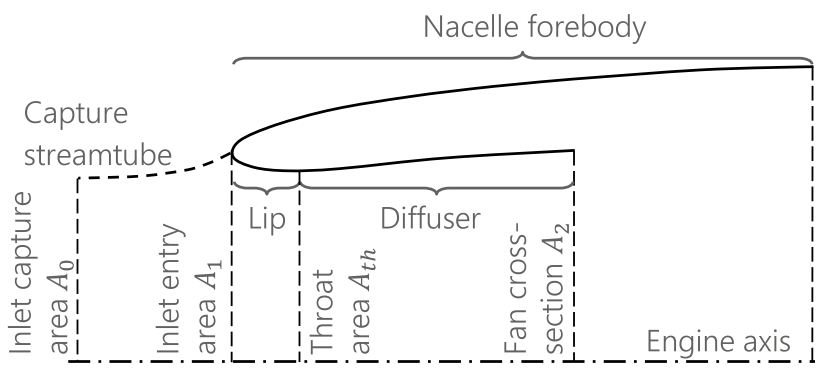

Fig. 2 Generic pitot inlet geometry 
chapter 3. Within the MorphElle project (morphing enabling technologies for propulsion system nacelles), different concepts for subsonic variable pitot inlets [3, 18-20] have been elaborated. In cooperation with the NASA, Kondor et al. have developed a further concept [4, 21, 22]. Moreover, many patents concerning variable inlets geometries exist, e.g., US5000399 [23] and US4075833A [24]. Nevertheless, the mentioned solutions are not used in modern aircraft yet.

The absence of applications with variable pitot inlets can be explained by the added function of variability, which requires additional or novel components, e.g., adjustment systems or elastic materials. These components can negatively influence the manufacturing costs and the mass of the system [25]. The increased mass also has a negative effect on the payload or range of the aircraft. Furthermore, the additional components of a variable system represent an increased risk for failures [25]. These can result in increased maintenance efforts, a shorter service life, and safety-critical events [26]. These disadvantages potentially outweigh the aerodynamic advantages of variable pitot inlets, so that aircraft manufacturers currently avoid applying them in current subsonic aviation.

Hence, within the scope of a feasibility study for variable inlet concepts, the methodological design process according to VDI 2221 [27] has been supplemented with the safety assessment process in aviation according to Aerospace Recommended Practices ARP 4754A [25]. The resulting development process comprises

- the review of relevant existing solution options for variable pitot inlets, compare chapter 3 ,

- the identification of ideal inlet geometries concerning drag and flow uniformity for different flight speeds up to Mach 1.6 and the potentially resulting aerodynamic benefit $[6,16]$,

- the development of concept groups that adjust the inlet geometry by adjustment of rigid segments, by deformation of elastic surface materials, or by boundary layer control [5, 28],

- the application of the safety methods Functional Hazard Assessment (FHA), Fault Tree Analysis (FTA), and Common Cause Analysis (CCA) [29, 30],

- integration studies concerning ice protection systems [31], as well as

- the manufacturing of functional prototypes to demonstrate the feasibility of the developed concepts [32, 33].

\subsection{Advantages compared to rigid pitot inlets}

The utilisation of variable pitot inlets provides numerous potential benefits for subsonic and supersonic aircraft in terms of fuel consumption, range, noise emissions, and operational safety.
During low-speed flight phases, such as take-off, goaround or climb, large angles of attack and severe crosswind conditions can lead to flow separation and non-uniform fan inflow, potentially along with many negative effects, e.g., loss of thrust. Using a variable inlet, which adapts the contour ideally to these conditions, the negative effects can be minimised. A variation of the lip geometry at these phases can achieve a reduced flow redirection and acceleration between the inlet entry area and throat area. As a result, turbulences, the frequency of compressible effects, and flow separations are reduced. This leads to a decreased noise generation, an increased inlet pressure recovery ratio, and a higher fan flow uniformity [10, 34]. A more uniform fan flow results in a higher fan efficiency and reduced fan noise. During low-speed flight phases, increasing the curvature (decreasing the radius) at the front of the outer nacelle forebody can also be beneficial to the inlet lip flow. An extension of the inlet can have a positive effect on the uniformity of the fan flow, as minor disturbances in the flow field can be smoothed out. An increase of the inlet entry area $A_{1}$ improves the matching with the capture stream tube at these low-speed flight phases. Thus, the necessary flow redirection around the inlet lip is reduced, which has similar effects to the lip geometry variation. An increased throat area $A_{t h}$ leads to lower throat Mach numbers, thereby local supersonic velocities and compressible effects can be avoided, leading to an improved inlet pressure recovery.

The improved resilience to flow separation and the higher flow uniformity due to variable inlets increase the surge margin and thus reduce the risk of engine surge [35]. The increased surge margin can also be used to achieve higher acceleration rates of the aero engine. This allows for shorter take-off distances, larger angles of attack, and increased climb rates. Consequently, the aircraft noise level and its duration can be decreased in the vicinity of the airport, positively impacting the aircraft certification and the operating costs at the airport. Additionally, the improved resilience to flow separation can increase the safety during severe crosswind conditions. This could also enable adjustments of the crosswind velocity limits according to CS 25.237 [26]. Moreover, the necessity of some aircraft for a rolling take-off could be avoided, allowing for shorter taxiways and thereby fuel savings.

During windmilling operation in case of an engine failure, the resulting spillage drag could be significantly reduced by a variable inlet that decreases the inlet entry area $A_{1}$. Due to the drag reduction, the remaining operating engines would also have to generate significantly less thrust. This could enable a reduction of the safety-related oversizing of aero engines.

For cruise flight, the influence of crosswinds is almost negligible due to the comparatively much higher flight speed. In addition, the usual angles of attack of civil 
applications are significantly smaller in cruise flight, thus permitting the assumption of a nearly undisturbed axial inlet flow. Hence, different circumferential cross-sections can be avoided during cruise flight and the entire inlet geometry can be optimised for these conditions. Moreover, for subsonic cruise flight, the inlet entry area $A_{1}$ could be reduced to better match the capture stream tube $A_{0}$. Consequently, the spill from the inlet lip to the outer nacelle forebody and the resulting drag are reduced. The geometry of the outer nacelle forebody could also be adapted to maximise the generated suction force [6]. This way, the resulting aircraft drag could be reduced, allowing for lower thrust requirements for the aero engines. Lower required thrust can enable lower fuel consumption and a longer flight range with an unchanged amount of fuel carried. The amount of fuel carried could also be reduced, thus increasing the payload of the aircraft. Furthermore, the drag reduction supports an increase of the cruise flight speed in the subsonic regime.

A further increase of the flight velocity up to supersonic velocities of Mach 1.6 requires additional geometry adjustments. Due to the normal shock in front of the inlet, no large suction force can be achieved on the nacelle forebody, so it is important to minimise its frontal area and to avoid additional shocks on the outer contour. However, the frontal area depends on the maximum nacelle diameter, which is limited by currently integrated accessories. Furthermore, the lip geometry should be as thin to sharp as possible, whereby the inlet throat relocates into the entry plane [36]. In this regard, the capability to reduce the lip length is beneficial. Simultaneously, a longer diffuser is also useful to smooth out local turbulences in the flow field after the initial normal shock. By adapting the inlet entry area $A_{1}$ to the required engine air mass flow, the distance between normal shock and inlet entry plane can be decreased [36]. This reduces the generated spillage drag significantly [36]. While the effects of a drag reduction are similar to subsonic cases, the potential benefit is much higher for supersonic conditions.

In contrast to rigid pitot inlets, variable pitot inlets offer increased resilience to flow separation at low flight speeds and the possibility to extend the operating range of aircraft towards more severe crosswind conditions. They can also support increased climb rates and thus reduce noise near the airport. Additionally, they enable more efficient subsonic and supersonic cruise flight. The variation of the inlet geometry could also be used as a de-icing mechanism. Due to the improved inlet flow, the generated noise can be reduced as well.

\subsection{Advantages compared to other inlet types}

Pitot inlets up to Mach 1.6 have numerous advantages compared to rectangular inlets with external compression, which have to compensate for the limited pressure recovery during supersonic operation. The main advantages are the low aerodynamic drag, the stable flow behaviour, and the high uniformity of the fan inflow $[9,11,39]$. The higher uniformity enables a significantly shorter inlet length and thus a reduction of the required installation space and mass [9]. Besides, a shorter length has a positive influence on the boundary layer thickness, thus avoiding the necessity of additional components like boundary layer separators. The stable flow behaviour includes in particular the fact that the compression shock is in a stable position due to the sharp lip [36]. In contrast, inlets with external or mixed compression may be subject to severe instabilities at the transition from subsonic to supersonic operation $[36,38]$. These instabilities can require complex starting and control mechanisms, such as movable flow duct walls or bypass doors [36, 38].

\section{Variable leading-edge solutions}

Given the potential advantages compared to limited rigid trade-off designs, there are numerous solution options for the variable design of wing leading edges and inlets. Partly, variable pitot inlets are the primary field of application for these solutions. However, most of them have been developed for other applications, but show a certain potential for application in variable pitot inlets.

Table 1 presents an overview of existing patents regarding variable geometries for wing leading edges and inlets. Additionally, it is shown which geometric parameters can be varied by the respective patents:

- the inlet entry area (A),

- the leading-edge curvature (R),

- the length of the aerofoil or inlet (L) and/or

- the thickness of the aerofoil or inlet (T),

on which functional principle the variation is based:

- adjustment of rigid surface segments of a continuous contour $(\mathbf{F})$,

- deformation of elastic surface materials $(\mathbf{E})$,

- moving of forebodies/flaps/ramps/cones (V) and/or

- aerodynamic boundary layer control (G),

for which spatial dimension the patents are mainly suitable:

- planar (2D) or

- annular (3D) applications,

as well as which potential weaknesses the respective patents reveal: 
Table 1 List of relevant patents

\begin{tabular}{|c|c|c|c|c|c|c|c|c|c|}
\hline Year & $\mathrm{Va}$ & ation & & & Principle & & & Description & References \\
\hline 2019 & A & $\mathrm{R}$ & & & $\mathrm{F}$ & & & Rotatable flaps, 3D, L, Z & [39] \\
\hline 2019 & & & $\mathrm{~L}$ & & & $\mathrm{~V}$ & G & Extendable cascades, 3D, L & {$[40]$} \\
\hline 2016 & & & & $\mathrm{~T}$ & $\mathrm{E}$ & & & Shape memory alloys, 2D & [41] \\
\hline 2016 & A & $\mathrm{R}$ & & $\mathrm{T}$ & $\mathrm{E}$ & & & Pneumatically adjustable elastomer, 3D, Z & {$[42]$} \\
\hline 2016 & A & & & $\mathrm{T}$ & $\mathrm{F}$ & & & Axially adjustable leading edge, $90^{\circ}$ sector & {$[43]$} \\
\hline 2016 & & & $\mathrm{~L}$ & & $\mathrm{~F}$ & & & Telescope principle, 3D, D & {$[44]$} \\
\hline 2016 & A & $\mathrm{R}$ & & $\mathrm{T}$ & $\mathrm{E}$ & & & Adjustable aerofoil, 2D, Z & {$[45]$} \\
\hline 2015 & A & $\mathrm{R}$ & & $\mathrm{T}$ & $\mathrm{E}$ & & & Adjustable aerofoil, 2D & {$[46]$} \\
\hline 2015 & & & $\mathrm{~L}$ & & $\mathrm{E}$ & & & Shape memory alloys, 2D, D & [47] \\
\hline 2014 & A & & & & $\mathrm{E}$ & & & Adjustable inlet lip, 3D, D & {$[48]$} \\
\hline 2014 & A & & & & & V & & Rotatable cone, $90^{\circ}$ sector & [49] \\
\hline 2014 & A & $\mathrm{R}$ & & $\mathrm{T}$ & $\mathrm{E}$ & & & Adjustable inlet lip, 3D, D & {$[50,51]$} \\
\hline 2014 & A & & & & & $\mathrm{V}$ & & Multiple fans, 2D & {$[52]$} \\
\hline 2014 & A & & & $\mathrm{T}$ & $\mathrm{F}$ & & & Segmented cowl, 3D, D & {$[53]$} \\
\hline 2014 & & & & & & & G & Boundary layer ingestion, 3D & {$[54]$} \\
\hline 2013 & A & $\mathrm{R}$ & & $\mathrm{T}$ & $\mathrm{E}$ & & & Segmented cowl, 3D, D & {$[55]$} \\
\hline 2013 & & & & & & V & G & Radially extendable aerofoils, 3D, D, L & {$[56]$} \\
\hline 2013 & & & & & & & G & Boundary layer suction, 3D, D, Z & {$[57]$} \\
\hline 2013 & & & & & & $\mathrm{~V}$ & & Tiltable rigid inlet, $3 \mathrm{D}, \mathrm{D}, \mathrm{Z}$ & {$[58]$} \\
\hline 2013 & & $\mathrm{R}$ & & $\mathrm{T}$ & & $\mathrm{V}$ & & Rotatable, overlapping inlet lip, 3D, D, Z & [59] \\
\hline 2013 & A & $\mathrm{R}$ & $\mathrm{L}$ & $\mathrm{T}$ & $\mathrm{E}$ & & & Pneumatically adjustable elastomer, $2 \mathrm{D}, \mathrm{Z}$ & {$[60]$} \\
\hline 2013 & & & & & & $\mathrm{~V}$ & G & Radially extendable aerofoils, 3D, D, L & {$[61]$} \\
\hline 2013 & A & & & & $\mathrm{E}$ & & & Shape memory alloys in nozzle, $\mathrm{D}$ & {$[62]$} \\
\hline 2012 & A & & & & & $\mathrm{V}$ & & Adjustable duct wall, 2D, D & {$[63]$} \\
\hline 2012 & & & & & & & G & Boundary layer suction, 3D, D & {$[64]$} \\
\hline 2012 & & & & & & & G & Boundary layer suction, 3D, D, Z & {$[65]$} \\
\hline 2012 & & & & & & $\mathrm{~V}$ & G & Radially extendable aerofoils, 3D, D, L & {$[66,67]$} \\
\hline 2012 & & & & & & $\mathrm{~V}$ & G & Movable vortex generators, 3D, D, Z & {$[68]$} \\
\hline 2012 & & & & & $\mathrm{~F}$ & & & Segmented leading edge, D & [69] \\
\hline 2012 & A & $\mathrm{R}$ & & $\mathrm{T}$ & $\mathrm{E}$ & & & Elastic wing deformation, 2D & {$[70]$} \\
\hline 2011 & A & $\mathrm{R}$ & & & $\mathrm{E}$ & & & Elastic deformation, 3D, D & {$[71]$} \\
\hline 2011 & & & & & & & G & Boundary layer injection, 3D, D & {$[72]$} \\
\hline 2010 & & & & & & $\mathrm{~V}$ & & Adjustable inlet flaps, D & [73] \\
\hline 2010 & & $\mathrm{R}$ & & & $\mathrm{E}$ & & & Elastic wing deformation, $2 \mathrm{D}, \mathrm{Z}$ & [74] \\
\hline 2010 & A & & & & & & & Inlet with turbochargers, 3D, Z, D & {$[75]$} \\
\hline 2009 & & & & & & & G & Vortex generators, 3D, D & [76] \\
\hline 2009 & & & & & & & G & Active boundary layer control, 3D, D & [77] \\
\hline 2009 & A & $\mathrm{R}$ & $\mathrm{L}$ & $\mathrm{T}$ & $\mathrm{E}$ & & & Elastic lip deformation, 3D, D & [78] \\
\hline 2009 & & & $\mathrm{~L}$ & & $\mathrm{~F}$ & & & Axially extendable inlet, 3D & [79] \\
\hline 2009 & A & & $\mathrm{L}$ & & & $\mathrm{V}$ & G & Axially extendable aerofoils, 3D & {$[80]$} \\
\hline 2009 & A & & $\mathrm{L}$ & & & $\mathrm{V}$ & G & Extendable lip ring, 3D & {$[81]$} \\
\hline 2008 & A & & $\mathrm{L}$ & & & $\mathrm{V}$ & $\mathrm{G}$ & Axially extendable aerofoils, 3D & {$[82]$} \\
\hline 2008 & & $\mathrm{R}$ & & $\mathrm{T}$ & $\mathrm{E}$ & & & Elastic deformation, 3D, D & [83] \\
\hline 2008 & A & & & & & $\mathrm{V}$ & & Variable center body, 3D, D & {$[84]$} \\
\hline 2006 & A & & & & $\mathrm{E}$ & & & Shape memory alloys in nozzle, D & {$[85]$} \\
\hline 2005 & A & $\mathrm{R}$ & $\mathrm{L}$ & $\mathrm{T}$ & & $\mathrm{V}$ & & Rotatable inlet in wing, 3D, D, Z & {$[86]$} \\
\hline 2005 & & $\mathrm{R}$ & $\mathrm{L}$ & & $\mathrm{E}$ & & & Adjustable inlet lip, 2D & [87] \\
\hline 2004 & A & & & & & $\mathrm{V}$ & & Adjustable duct wall, 2D & {$[88]$} \\
\hline 2004 & & & & & & $\mathrm{~V}$ & & Rotatable and tiltable inlet, 3D, D & [89] \\
\hline 2003 & & & & & $\mathrm{E}$ & & & Flexible surface, D & [90] \\
\hline 2003 & A & & & & & $\mathrm{V}$ & & Blockage flaps, 3D, D, Z, L & [91] \\
\hline
\end{tabular}


Table 1 (continued)

\begin{tabular}{|c|c|c|c|c|c|c|c|c|c|}
\hline \multirow{2}{*}{$\frac{\text { Year }}{2002}$} & \multicolumn{4}{|c|}{ Variation } & \multicolumn{3}{|l|}{ Principle } & \multirow{2}{*}{$\begin{array}{l}\text { Description } \\
\text { Internal compression inlet, 2D }\end{array}$} & \multirow{2}{*}{$\frac{\text { References }}{[92]}$} \\
\hline & A & & & $\mathrm{T}$ & $\mathrm{F}$ & & & & \\
\hline 2001 & A & $\mathrm{R}$ & & & $\mathrm{E}$ & & & Segmented elastomer, 3D, D & [93] \\
\hline 2000 & A & & & & & $\mathrm{V}$ & & Bleed doors, 3D, $\mathrm{L}$ & [94] \\
\hline 1999 & A & & & & & $\mathrm{V}$ & & Bleed doors, 2D, D, L & [95] \\
\hline 1994 & A & & & & & V & & Variable center body, 3D & [96] \\
\hline 1992 & A & $\mathrm{R}$ & & $\mathrm{T}$ & & $\mathrm{V}$ & & Bleed doors, 3D, D, L & {$[97]$} \\
\hline 1992 & A & & & & & $\mathrm{V}$ & & Adjustable duct wall, 2D & [98] \\
\hline 1991 & A & $\mathrm{R}$ & & $\mathrm{T}$ & $\mathrm{F}$ & & & Segmented adjustable inlet lip, 3D, Z, L & {$[23]$} \\
\hline 1989 & A & $\mathrm{R}$ & & $\mathrm{T}$ & & $\mathrm{V}$ & & Adjustable flaps, 3D, D, L & [99] \\
\hline 1988 & A & & & & & $\mathrm{V}$ & $\mathrm{G}$ & Bleed doors, 3D, $\mathrm{L}$ & {$[100]$} \\
\hline 1987 & A & & & & & $\mathrm{V}$ & & Adjustable duct wall, 2D & {$[101]$} \\
\hline 1986 & A & & & & & $\mathrm{V}$ & G & Bleed doors, 3D & [102] \\
\hline 1984 & A & & & & & $\mathrm{V}$ & $\mathrm{G}$ & Bleed doors, 3D & [103] \\
\hline 1984 & A & $\mathrm{R}$ & $\mathrm{L}$ & $\mathrm{T}$ & $\mathrm{E}$ & & & Adjustable aerofoil, 2D & [104] \\
\hline 1982 & A & $\mathrm{R}$ & & $\mathrm{T}$ & $\mathrm{E}$ & & & Adjustable aerofoil, 2D & {$[105]$} \\
\hline 1979 & A & $\mathrm{R}$ & $\mathrm{L}$ & $\mathrm{T}$ & $\mathrm{F}$ & & & Bleed doors, 3D, L & [106] \\
\hline 1978 & A & $\mathrm{R}$ & & $\mathrm{T}$ & $\mathrm{F}$ & & & Segmented adjustable inlet lip, 3D, Z & [24] \\
\hline 1977 & A & $\mathrm{R}$ & & $\mathrm{T}$ & $\mathrm{E}$ & & & Adjustable inlet lip, 2D & {$[107]$} \\
\hline 1975 & & & & & & $\mathrm{~V}$ & & Adjustable internal inlet rings, 3D & [108] \\
\hline 1975 & A & & & & $\mathrm{F}$ & & $\mathrm{G}$ & Bleed doors, 2D & [109] \\
\hline 1973 & A & & & & & $\mathrm{V}$ & & Rotatable flaps, 3D, L, Z & [110] \\
\hline 1973 & A & & & & $\mathrm{F}$ & & & Adjustable segmented inlet lip, 3D, D & [111] \\
\hline 1972 & A & $\mathrm{R}$ & $\mathrm{L}$ & $\mathrm{T}$ & $\mathrm{F}$ & & G & Adjustable segmented inlet lip, 3D, L, Z & [112] \\
\hline 1971 & A & $\mathrm{R}$ & & $\mathrm{T}$ & $\mathrm{F}$ & & G & Adjustable segmented inlet lip, 3D, D & [113] \\
\hline 1970 & & $\mathrm{R}$ & & $\mathrm{T}$ & & $\mathrm{V}$ & & Rotatable inlet in fuselage, $3 \mathrm{D}, \mathrm{D}, \mathrm{Z}$ & [114] \\
\hline 1969 & A & $\mathrm{R}$ & $\mathrm{L}$ & & & $\mathrm{V}$ & & Tiltable rigid inlet, 2D, D & {$[115]$} \\
\hline 1966 & A & $\mathrm{R}$ & $\mathrm{L}$ & $\mathrm{T}$ & $\mathrm{F}$ & & & Rotatable segmented inlet lip, 3D, L, Z & [116] \\
\hline
\end{tabular}

- an insufficient degree of detail (D),

- high noise emissions, e.g. due to exposed flaps (L) or

- very high complexity or functional weaknesses that can lead to a reduced reliability of the system $(\mathbf{Z})$.

Numerous models for the structured classification of patents exist [117]. In the following, the primary differentiation is based on the spatial dimension of the application and the subsequent subdivisions are made according to the associated component and the type of geometry variation, compare Fig. 3.

Generating variable geometries is considerably easier for plane structures than for annular structures in threedimensional space. Hence, many applications of planar 2D solutions exist in the shape of variable wing designs and variable rectangular supersonic inlets. In the threedimensional space, different variable solutions exist for the center body and for the inlet cowl, especially for supersonic applications. Thereby, most of the solutions

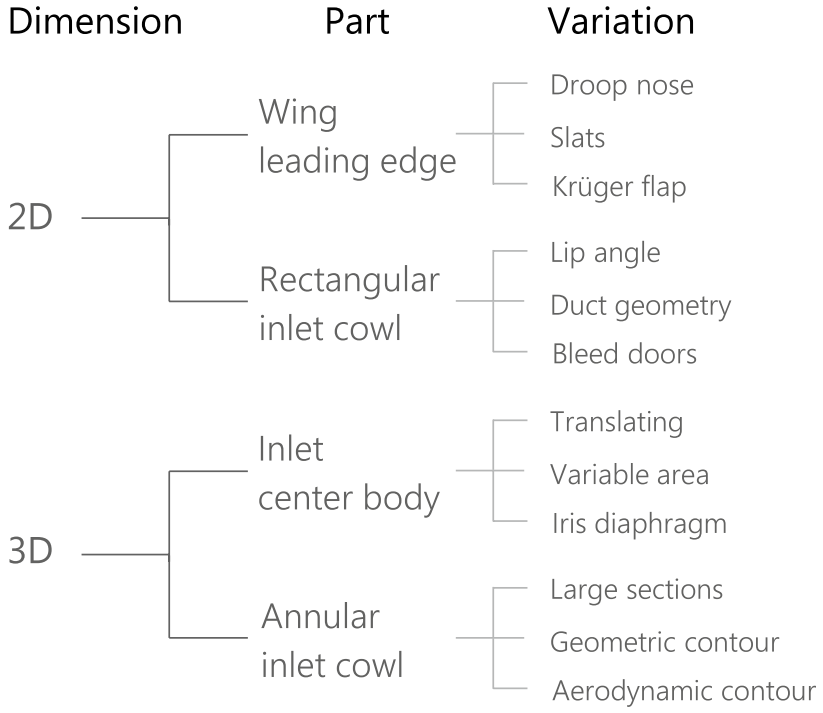

Fig. 3 Overview variable solution principles 
in the field of the inlet cowl have never surpassed the status of a patent idea.

\subsection{Variable wing leading edge}

Aerofoils of aircraft wings represent high-lift systems, in which the curvature and the projected area are maximised, while the risk of flow separation is minimised [34]. In this context, gapless applications with continuous contours and those with gaps can be found [34]. Especially in the region of the leading edge, the emphasis is on the prevention of flow separations [34]. Therefore, the surface contour is designed in an aerodynamically smooth way and the flow accelerations in the lip region are limited. [34].

Niu [118] summarises the various solution options for the geometry variation of aircraft wing leading edges. These solutions can be categorised into three main types, which are illustrated in Fig. 4:

- the droop nose [34, 118],

- slats $[34,60,118]$, and

- the Krüger flap [34, 118].

Furthermore, there are combinations of droop nose and Kruger flap [104].

Whereas concepts for adjustable slats and Krüger flaps generate considerable amounts of noise due to their gap involving design, modified droop nose concepts $[45,46$, $70,74,105]$ could also be applied for the lip of a pitot inlet. In particular, the adaptation of the geometry variation from the almost flat aircraft wing to the three-dimensional, annular shape of the pitot inlet presents a considerable technical challenge. Recent studies [119-122] on

\section{Droop Nose}

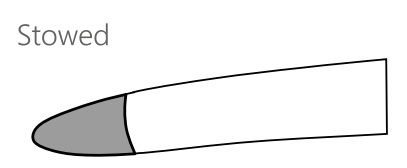

Deployed

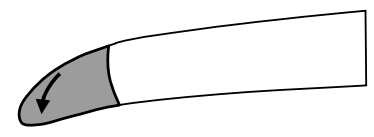

Slats
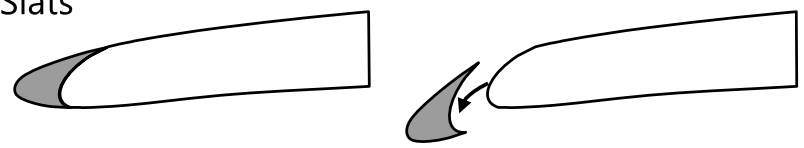

\section{Krüger flap}
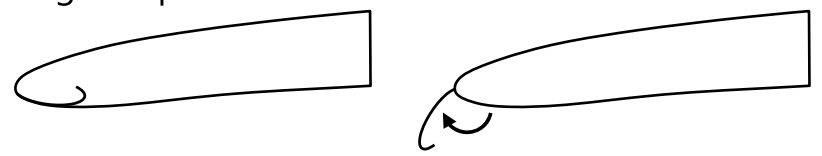

droop nose implementations by means of smart materials could assist this adaptation.

\subsection{Variable rectangular inlet cowl}

As shown in Fig. 5, the nacelle geometry of rectangular inlets for supersonic applications can be varied by

- adjusting the lip shape and angle,

- modifications of the flow duct geometry, and

- bleed doors or flaps within the duct [123]

The variation of the lip angle and lip shape $[87,107]$ is comparable to the solution approaches for variable aircraft wing leading edges, especially to the droop nose. The lip variation provides an adaptation to the capture stream tube, to the inflow direction and enables the desired shock configurations [9]. As an example, variable metallic inlet lips are installed in the F-15 and Eurofighter aircraft [9]. The Hawker P1127 featured inflatable rubber inlet lips; however, due to their limited service life, these were later replaced by metallic designs [9]. Smart materials also offer considerable potentials that have been investigated, for instance, in the SAMPSON project (Smart Aircraft and Marine Project System Demonstration) [124-128].

The variation of the flow duct geometry $[63,92,101]$ allows to control the engine mass flow, as well as the position and the intensity of occurring compression shocks, mitigating the difficulties concerning the starting of supersonic inlets $[10,36]$. The variation of the duct geometry is often combined with flaps, blow-in doors, or bleed doors

\section{Lip angle}

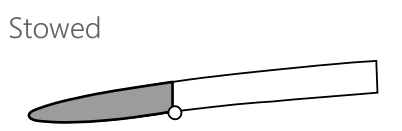

\section{Deployed}

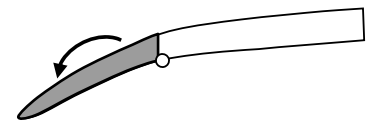

\section{Duct geometry}
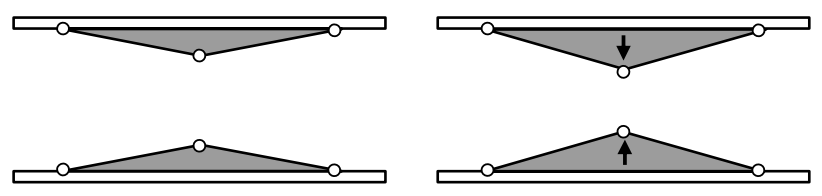

Bleed doors
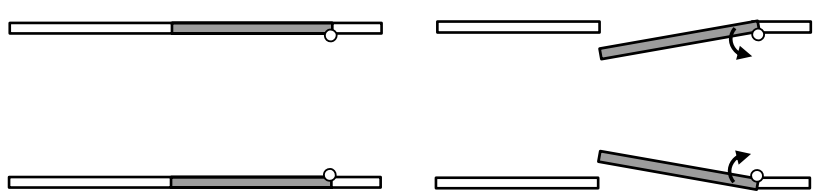

Fig. 5 Variable geometries for rectangular inlet cowls

Fig. 4 Variable high-lift systems on aircraft wings 
$[88,95,107]$. By means of these vents, additional required air can flow into the inlet or excessive air can be ventilated from the inlet. Depending on the door design, flow separation can be avoided by boundary layer suction or ingestion. Blow-in and bleed doors have also been installed in former pitot inlets; however, they entail the disadvantage of considerable noise generation [9].

\subsection{Variable inlet center body}

The variation of the conical center body is primarily used for supersonic inlets with mixed compression to create the intended shock configurations. Hereby, the center body can be axially movable $[84,96]$ or provide an adjustable diameter [96, 123], see Fig. 6. Moreover, vent ducts for boundary layer suction are often integrated into adjustable center bodies [9].

A further option to vary the inlet cross section is the use of the iris diaphragm principle. This principle is similar to a camera iris, where the opening cross section is adjusted,

\section{Translating}

Stowed
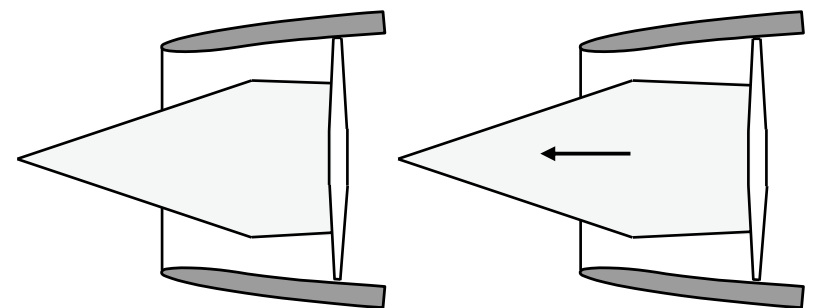

Variable area
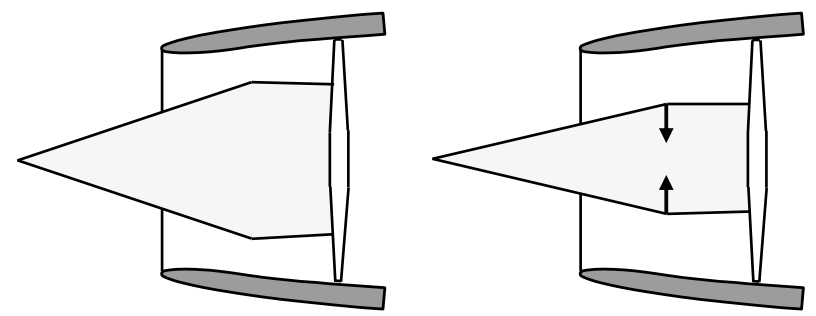

Iris diaphragm
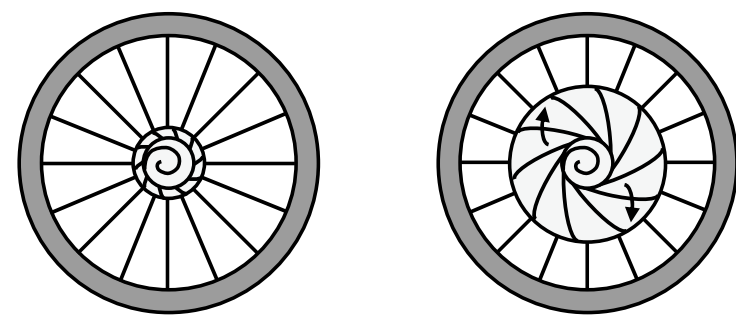

Fig. 6 Variable inlet center body solutions see Fig. 6 bottom. This solution principle is applied in the Sukhoi Su-29 [129].

\subsection{Variable annular inlet cowl}

There are three basic approaches for the implementation of variable pitot inlet cowls, compare Fig. 3. The first of these approaches is the variation of the inlet by moving large components. This involves the tilting, rotation, or extension of large sections or components of the inlet cowl. Furthermore, there is a concept option [89], where the inlet can be rotated and tilted simultaneously.

Concept variations for the tilting of large areas of the inlet cowl have been developed, which tilt the entire inlet $[58,115]$ or only a large sector of the inlet [115] along an axis, see Fig. 7. For instance, these variants can be used to adapt to different angles of attack or to block the fan noise from the ground.

The rotation of large components represents a further solution option. Hereby, the entire inlet ring or the inlet lip is rotated around the engine axis [59, 114], see Fig. 8, or around an offset axis [86]. This solution is particularly useful for engines whose inlet is semi-circular and mounted close to the fuselage. In this way, a more suitable geometry can be set for the respective flight phase, while the less favourable geometry is stowed inside of the fuselage. Within the HISAC

Tiltable inlet ring

Stowed

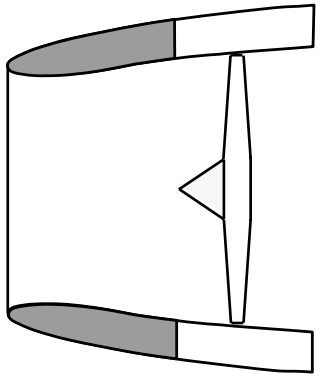

Deployed

Tiltable inlet sector
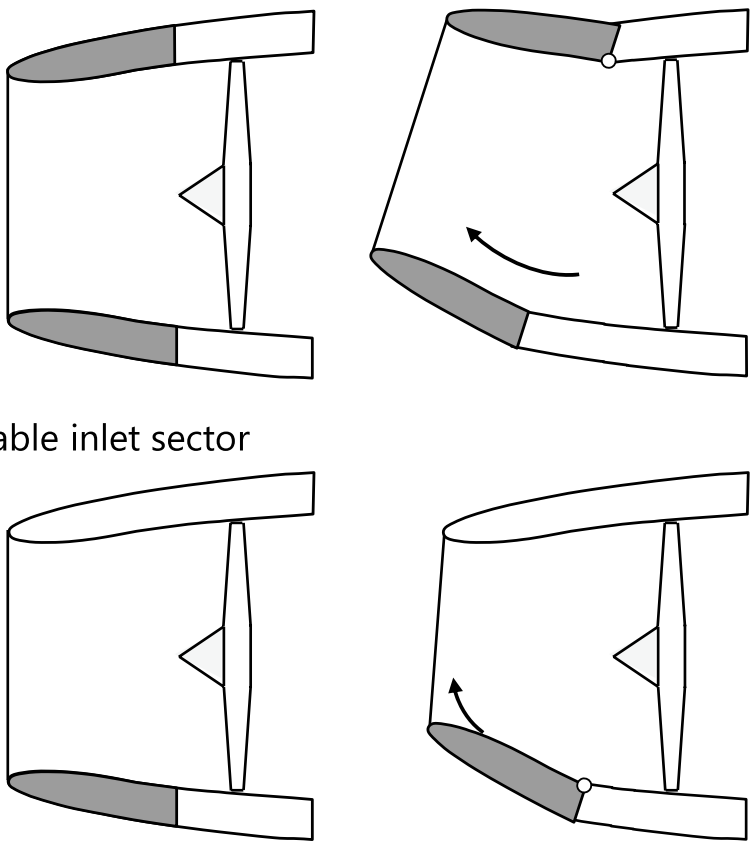

Fig. 7 Tiltable pitot inlet options 


\section{Rotation around engine axis}

State 1
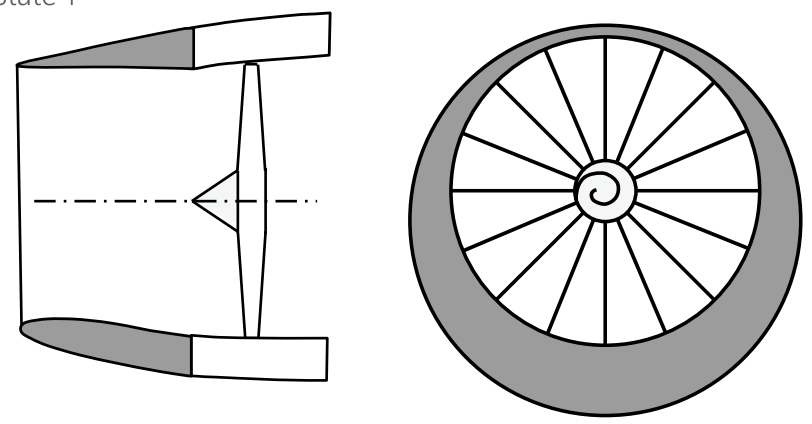

State 2
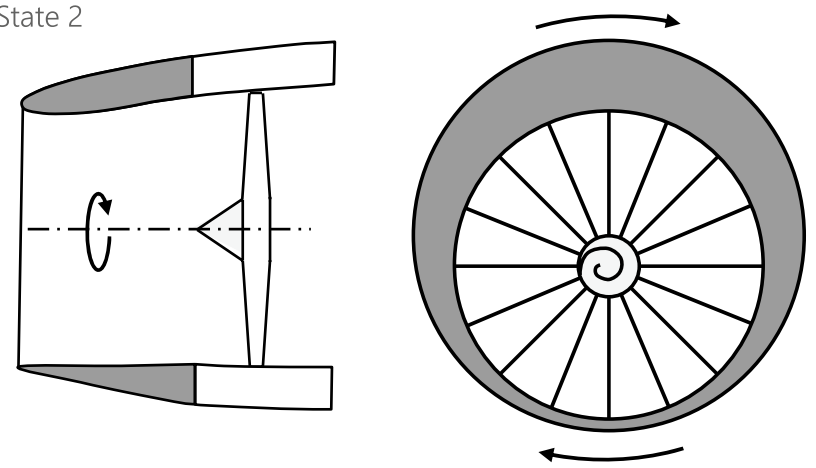

Fig. 8 Example of a rotatable pitot inlet

project different inlet configurations with semi-circular and circular inlets have been investigated in detail [37].

The extension of large annular inlet components can be achieved using the telescopic principle [44, 79], by axial translation of an inlet lip ring [81, 82], or by axial translation of vane rings out of the lip [40, 80], see Fig. 9. The telescopic principle describes the idea of having a part of the inlet stowed inside the inlet cowl in its nominal state and being able to deploy this part to create a part of the inlet contour when required. Using this principle, only the length of the inlet can be varied. The solutions of translating inlet lips or vanes are functionally comparable to the principle of the opening flaps, blow-in doors, or bleed doors in the flow duct, compare Fig. 5 bottom. Hereby, the goal is to maximise the incoming air mass flow, while avoiding flow separations. A major challenge presents the resulting noise from the flow around the extended components.

Axially adjustable rings within the inlet duct [108] represent an special option for the redirection of the inlet flow and to provide design space for acoustic treatment. However, the influence of these rings on the inlet flow is to investigate.

The concepts that vary the geometry of the inlet by moving large components are mainly characterised by their simple kinematics. However, the disadvantage of these concepts is that the degree of the geometry variation is very limited.
Telescope principle

Stowed

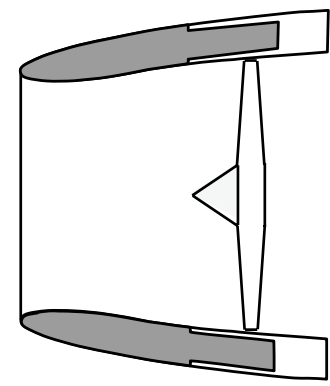

Deployed

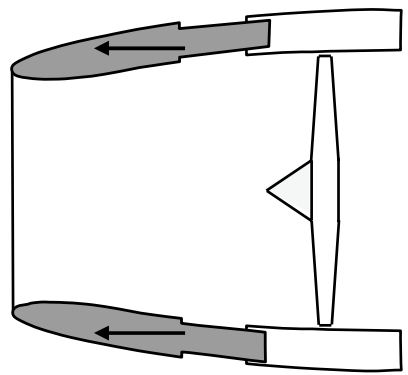

Translating ring
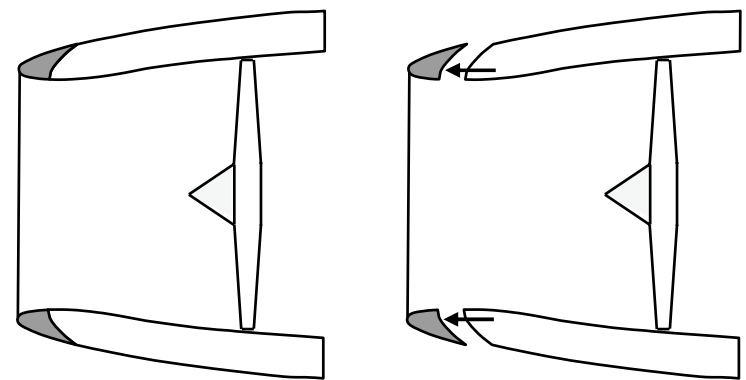

Translating vanes
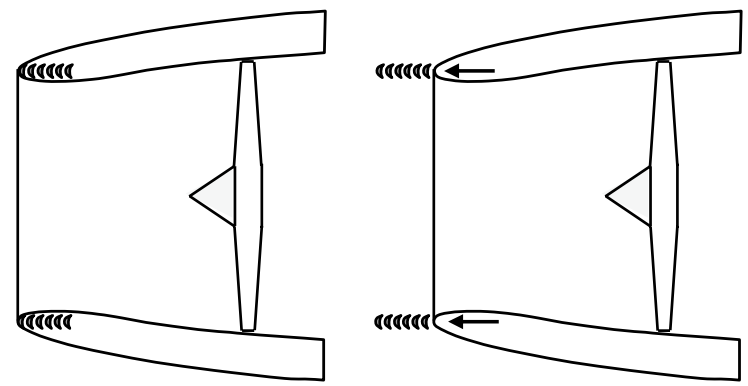

Fig. 9 Inlet variation by axial extension

The functionality of these concepts must be investigated as well. The level of detail of most of these concepts is also too low to be able to estimate their feasibility. For moving very large and hence heavy components, equally large actuating forces are necessary as well. Furthermore, the components of the adjustment system must be dimensioned accordingly.

The second basic approach for the implementation of variable pitot inlet cowls, namely the geometrical contour variation, offers greater aerodynamic potential. This approach comprises concepts with accepted surface gaps and steps on one hand, and concepts that provide almost gapless continuous contours on the other hand. Both concept types must be clearly distinguished from each other, as the former concept type usually features simpler kinematics, but generates more noise due to the created turbulence at the gaps and steps. 
The geometrical variation requires movements of rigid surface components or elastic deformations of the surface material in the radial direction. Due to the annular structure of pitot inlets, radial variations of rigid components can cause circumferential gaps or component collisions. These gaps and collisions can be avoided by a circumferential segmentation of the components, including a sealing between the resulting segments. Potential solutions for circumferential sealings range from the acceptance of gaps [116] over rigid borders between the segments $[24,111]$ and overlapping adjacent segments [53] up to elastic material between the segments [23].

Examples of concepts with accepted or even desired surface gaps are

- radial adjustable vanes,

- adjustable inlet flaps, as well as

- blow-in and bleed doors, compare Fig. 10

Adjustable vanes can be moved radially inwards $[61,67]$ as well as radially outwards $[56,66,67]$. A combination with an axial translation [82] is also possible. As with the previously described solutions with movable vanes, the aim of these concepts is to maximise the incoming air mass flow and to minimise the occurrence of flow separations.

Adjustable inlet flaps can be installed on the outside of the inlet $[39,100]$ to create a bell-mouth-like geometry that is resilient to flow separations [10]. The flaps can also be mounted on the inside [91] or in front of inlet [97], for instance, to regulate the air mass flow.

Blow-in and bleed doors within the pitot inlet cowl enable an adjustment of the effective inlet entry area by ingestion of additional required air $[94,106,112,113]$ or by ventilation of excessive air from the inlet [97, 100, 102, 103]. Thereby, the boundary layer is influenced positively, leading to a reduced risk of flow separation. The main difference between the doors for annular applications compared to those for rectangular inlets is that the doors can only cover a relatively small circumferential sector. Otherwise, the gap losses between the rotating flaps and the curved rigid inlet structure would increase significantly.

Concepts that achieve a continuous contour can be based on the principles of adjusting rigid contour segments or the elastic deformation of the surface material. Both solutions enable the fundamental variation of all geometrical parameters of the inlet cowl.

The principle of moving rigid segments comprises solution options for the adjustment of the inlet lip [23, 24, 111], the diffuser geometry $[24,53]$, as well as the outer contour [23]. Although, there is currently no according patent that can vary the geometry of all these three parts. For solutions that can vary the lip geometry and the inlet entry area, a higher risk of damage due to bird strikes must be considered.

\section{Radial vanes}

Stowed

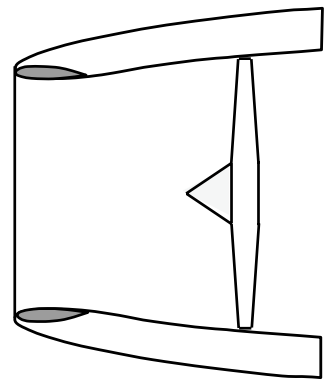

Deployed

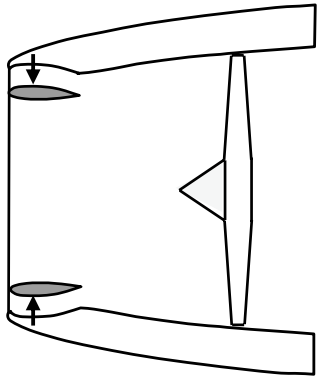

Inlet flaps

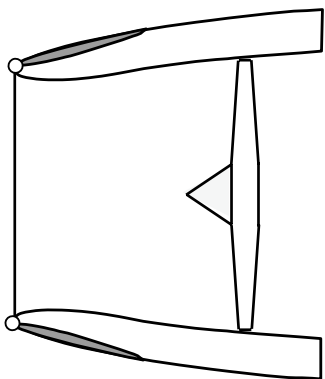

Bleed doors
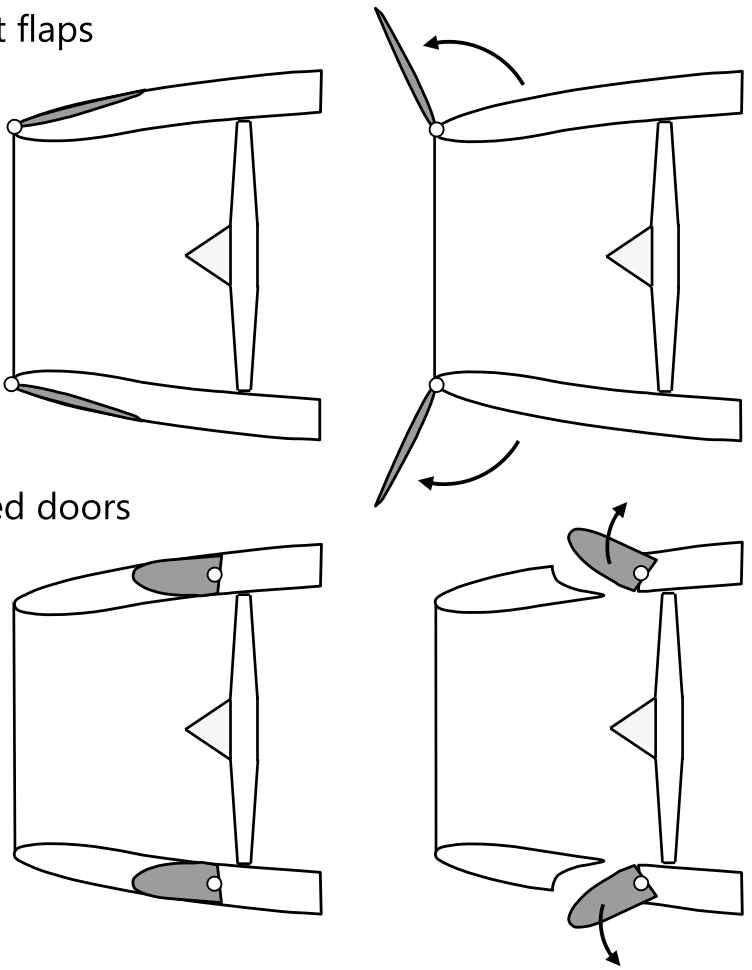

Fig. 10 Variable vanes and flaps

However, two of the mentioned lip adjusting solution options $[24,111]$ utilise a segmented lip, which is particularly fragile in the event of a bird strike. The remaining solution [23] uses a circumferentially continuous ring as leading edge of the inlet lip, compare Fig. 11. This ring is axially translated to adjust the segmented outer contour. During this movement, a safety-critical gap arises between inner and outer geometry at the inlet entry plane [23]. For the implementation of cross-sectional variations, the displacement of rigid contour segments always requires a circumferential segmentation of the contour. This leads to an increase of the design complexity and results in small circumferential deviations from an ideal circular geometry.

For the principle of elastic surface deformation, segmented [55, 93] and circumferentially continuous [42, 48, 


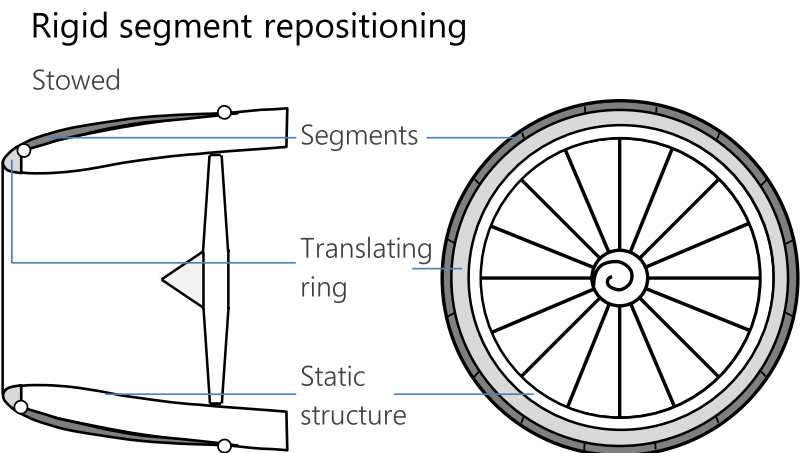

Deployed
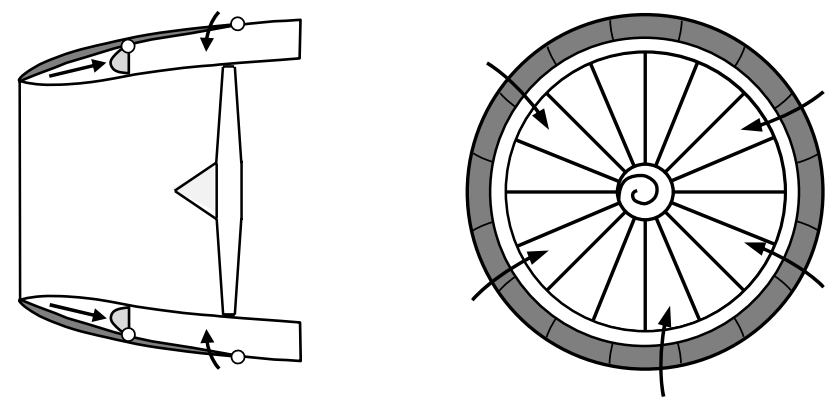

Fig. 11 Adjustment of rigid inlet segments

$50,51,71,78,83]$ solution options exist. The segmented solutions that use this principle are comparable to the previously described concepts that adjust rigid segments. Thereby, the elastic surface material enables a smoother contour in the axial direction, while being more prone to heavy wear. Furthermore, the range of the achievable geometrical adjustments is comparatively small.

Circumferentially continuous solution options achieve the aerodynamically best inlet geometries by avoiding circumferential deviations from the ideal contour. For this purpose, the material must be able to expand in axial and circumferential directions. In this context, smart materials [83] or pneumatically deformable contour cells [42] could be utilised. The later principle is also used in the concept developed in the MorphElle project [3, 18-20]. When considering these pressurised contour cells, emphasis should be placed on their durability and resilience to erosion, foreign object damage, and bird strikes.

The third basic approach for the implementation of variable pitot inlet cowls is the control of the flow boundary layer [130]. By avoiding flow separations, boundary layer control allows the use of slim geometries with low aerodynamic drag [131]. Solutions for boundary layer control can be divided into passive and active mechanisms [34].

Passive mechanisms include, for instance, the introduced applications concerning adjustable vanes and bleed doors [132]. Solutions with bleed doors [97, 100, 102, 103] direct the flow in the vicinity of the duct wall through openable
Boundary layer suction
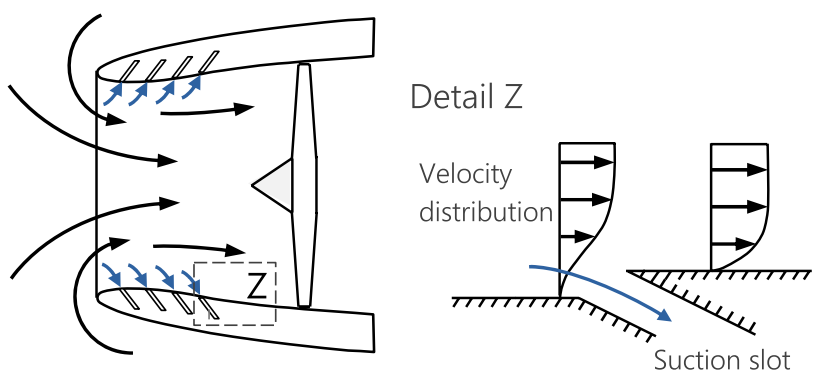

Boundary layer blowing
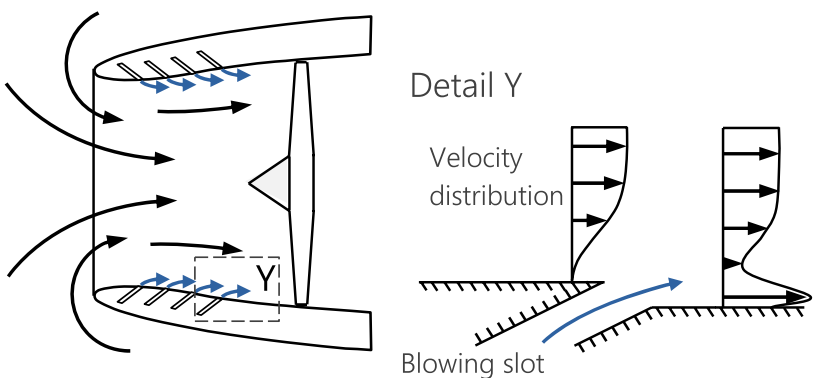

Fig. 12 Options of boundary layer control

flow ducts to the outside of the inlet [132], compare Fig. 5 bottom and FIGURE 9 centrally. Similar to slats [34], adjustable aerofoils or vanes [40, 56, 61, 66, 67, 82, 99] prevent flow separations, compare Fig. 9 bottom and Fig. 10 top. A special case of vanes is vortex generators, which are integrated into the flow duct. These are intended to avoid flow separations by increasing the turbulence of the flow. Vortex generators can be designed as stationary [76] or extendable [68].

Active boundary layer control includes the suction of the flow boundary layer through small suction slots [57, 64], the tangential blowing into the boundary layer through blowing slots [54, 72], and combinations [65] of these types [34, 133], compare Fig. 12. The concept of Kondor et al. [4, 21, 22] also uses the principle of tangential blowing into the boundary layer. By blowing in or suctioning off air, the flow boundary layer is stabilized in the vicinity of the wall and flow separation is avoided [34]. A challenge for these concepts poses the protection of the respective slots from dirt or ice blockage. Additionally, a control system is required to regulate the air mass flow to be supplied or removed. For the event of a malfunction of the system, design precautions must be taken to ensure that the inlet still fulfils its function.

\subsection{Relevance for variable pitot inlets}

For the evaluation of the relevance of a solution option for variable pitot inlets, the most important advantages and 
Table 2 Evaluation of relevance for variable pitot inlets

\begin{tabular}{|c|c|c|c|}
\hline Component & Type of variation & Benefits & Weaknesses \\
\hline \multirow[t]{3}{*}{ Wing leading edge } & Droop nose & $\begin{array}{l}\text { Stepless surface, good drag reduction, } \\
\text { avoidance of flow separation }\end{array}$ & Only $2 \mathrm{D}$, reliability \\
\hline & Slats & $\begin{array}{l}\text { Proven technology, avoidance of flow } \\
\text { separation, simple kinematic }\end{array}$ & $\begin{array}{l}\text { Only 2D, large gaps, increased turbu- } \\
\text { lences, and noise }\end{array}$ \\
\hline & Krüger flap & $\begin{array}{l}\text { Proven technology, avoidance of flow } \\
\text { separation, simple kinematic }\end{array}$ & $\begin{array}{l}\text { Only } 2 \mathrm{D} \text {, large steps, increased turbu- } \\
\text { lences, and noise }\end{array}$ \\
\hline \multirow[t]{3}{*}{ Rectangular inlet cowl } & Lip angle & $\begin{array}{l}\text { Stepless surface, good drag reduction, } \\
\text { avoidance of flow separation }\end{array}$ & Only $2 \mathrm{D}$, reliability \\
\hline & Duct geometry & Mass flow control & Only 2D, low drag reduction \\
\hline & Bleed doors & Avoidance of flow separation & $\begin{array}{l}\text { Only } 2 \mathrm{D} \text {, low drag reduction, increased } \\
\text { turbulences and noise }\end{array}$ \\
\hline \multirow{3}{*}{$\begin{array}{l}\text { Inlet } \\
\text { center body }\end{array}$} & Translating & Mass flow control, simple kinematic & Low drag reduction, weight \\
\hline & Variable area & Mass flow control & No drag reduction, complexity, weight \\
\hline & Iris diaphragm & Mass flow control & No drag reduction, complexity \\
\hline \multirow[t]{8}{*}{ Annular inlet cowl } & Tiltable large sections & Avoidance of flow separation & Low drag reduction, weight \\
\hline & Rotatable large sections & $\begin{array}{l}\text { Good drag reduction, avoidance of } \\
\text { flow separation }\end{array}$ & Complexity, weight \\
\hline & Extension of large sections & Simple kinematic & Low drag reduction, weight \\
\hline & $\begin{array}{l}\text { Geometric contour with flaps, steps, } \\
\text { and/or gaps }\end{array}$ & Avoidance of flow separation & $\begin{array}{l}\text { Low drag reduction, increased turbu- } \\
\text { lences, and noise }\end{array}$ \\
\hline & $\begin{array}{l}\text { Continuous geometric contour with } \\
\text { rigid segments }\end{array}$ & $\begin{array}{l}\text { Good drag reduction, avoidance of } \\
\text { flow separation }\end{array}$ & $\begin{array}{l}\text { Complexity, reliability, remaining small } \\
\text { steps and gaps }\end{array}$ \\
\hline & $\begin{array}{l}\text { Continuous geometric contour with } \\
\text { elastic surface }\end{array}$ & $\begin{array}{l}\text { Good drag reduction, avoidance of } \\
\text { flow separation }\end{array}$ & $\begin{array}{l}\text { Complexity, reliability, durability, } \\
\text { remaining small steps and gaps }\end{array}$ \\
\hline & Passive boundary layer control & Avoidance of flow separation & $\begin{array}{l}\text { Low drag reduction, increased turbu- } \\
\text { lences, and noise }\end{array}$ \\
\hline & Active boundary layer control & $\begin{array}{l}\text { Good drag reduction, avoidance of } \\
\text { flow separation }\end{array}$ & $\begin{array}{l}\text { Complexity, reliability, fail-safe mecha- } \\
\text { nisms }\end{array}$ \\
\hline
\end{tabular}

disadvantages of the respective type of variation are listed in Table 2.

Thereby, solutions have been eliminated, which are solely developed for planar or two-dimensional applications, compare Fig. 4, 5. On one hand, 2D solutions with the same mass and length provide worse flow uniformity and aerodynamic drag compared to annular solutions. On the other hand, adapting the principles to a circular contour would lead to increased complexity and thus reliability issues.

Solutions, which vary the inlet center body (Fig. 6), have also been excluded, as they cannot provide a significant drag reduction in the investigated velocity range. Another challenge is presented by their increased complexity and weight.

Tilting (Fig. 7), rotation (Fig. 8), or extension (Fig. 9) of large sections requires large actuating forces, resulting in increased weight. While the rotation of large sections is very complex, tilting and extension of large sections can only provide small aerodynamic drag improvements.

All solution options, which utilise geometrical contour variation or boundary layer control for an annular inlet cowl, provide means to avoid flow separation and can achieve high uniformity. Options that vary the geometrical contour with flaps, steps, and/or gaps (Fig. 10), as well as passive boundary layer control result in increased turbulences and noise due to the flaps, steps, and/or gaps. Furthermore, these options can only provide low drag reduction.

Solutions with nearly gap- and stepless geometrical contour variation either using rigid segments (Fig. 11) or an elastic surface material achieve reduced drag at cost of increased complexity and potential reliability issues. Additionally, the influence of the remaining small surface steps and gaps on the aerodynamic properties of these inlets must be investigated with solutions of a higher degree of detail. Active boundary layer control (Fig. 12) presents a further aerodynamically suitable option. However, detailed investigations are necessary to ensure the safety and reliability of this option. 


\section{Conclusions}

The motivation for designing variable pitot inlets for future supersonic transport (SST) has been described. An overview of existing technological solutions for variable leading edges of aircraft wings and engine inlets has been given. The advantages and limitations of over 80 solutions, as well as their relevance for application on variable pitot inlets for SST have been identified. In this context, different solution categories have been established. These categories are based on the spatial dimension of the application, the associated component, and the type of variation.

Most of the identified solutions offer potential benefits for improvements of the inlet flow. However, all approaches have individual weaknesses regarding the fulfilment of requirements, e.g., flow characteristics, noise emissions, reliability, or safety. These weaknesses can be caused by unsuitable design methodologies, a low level of detail, and/ or insufficient experience with innovative technologies.

The most suitable options for variable pitot inlets are represented by concepts that adjust the inlet geometry by

- repositioning of rigid inlet cowl segments of a continuous contour,

- elastic deformations of the inlet cowl surface material, and

- by active boundary layer control.

These results may assist further investigations concerning variable inlets in the context of research and development programmes with a high potential for application in supersonic aircraft. This way, the aircraft range could be significantly increased, and their fuel consumption reduced. This would result in considerable economic and ecological improvements. Thus, variable pitot inlets could become a key factor in the reintroduction of a more environmentally friendly supersonic transport.

Funding Open Access funding enabled and organized by Projekt DEAL.

Open Access This article is licensed under a Creative Commons Attribution 4.0 International License, which permits use, sharing, adaptation, distribution and reproduction in any medium or format, as long as you give appropriate credit to the original author(s) and the source, provide a link to the Creative Commons licence, and indicate if changes were made. The images or other third party material in this article are included in the article's Creative Commons licence, unless indicated otherwise in a credit line to the material. If material is not included in the article's Creative Commons licence and your intended use is not permitted by statutory regulation or exceeds the permitted use, you will need to obtain permission directly from the copyright holder. To view a copy of this licence, visit http://creativecommons.org/licenses/by/4.0/.

\section{References}

1. European Commission: European Aeronautics. A vision for 2020. Office for Official Publications of the European Communities, Luxembourg (2001)

2. European Commission: Flightpath 2050. Europe's vision for aviation. Publications Office of the European Union, Luxembourg (2011)

3. Kling, U., Seitz, A., Bijewitz, J., Hermanutz, A., da RochaSchmidt, L., Scarpa, F., Majić, F., Efraimsson, G., O’Reilly, C.J.: Shape adaptive technology for aircraft engine nacelle inlets. In: Proceedings of the Royal Aeronautical Society's 5th Aircraft Structural Design Conference (2016)

4. Kondor, S., Englar, B., Lee, W., Moore, M.: Experimental investigation of circulation control on a shrouded fan. In: 21st AIAA Applied Aerodynamics Conference (2003)

5. Kazula, S., Höschler, K.: Evaluation of variable pitot inlet concepts for transonic and supersonic civil aviation. AEAT 92(6), 807-815 (2020). https://doi.org/10.1108/AEAT-11-2019-0225

6. Kazula, S., Wöllner, M., Grasselt, D., Höschler, K.: Parametric design and aerodynamic analysis of circular variable aero engine inlets for transonic and supersonic civil aviation. In: Proceedings of the 24th International Symposium on Air Breathing Engines (ISABE-2019-24018) (2019)

7. Benson, T.J., Seidel, J.A.: Gas Turbine Engines: Inlets. In: Blockley, R., Shyy, W. (eds.) Encyclopedia of aerospace engineering, vol. 137. Wiley Interscience, Hoboken, NJ (2010)

8. Rick, H.: Gasturbinen und flugantriebe: grundlagen, betriebsverhalten und simulation. In: VDI-Buch. Springer, Berlin, Germany (2013)

9. Sóbester, A.: Tradeoffs in jet inlet design: a historical perspective: a historical perspective. J. Aircr 44(3), 705-717 (2007). https://doi.org/10.2514/1.26830

10. Bräunling, W.J.G.: Flugzeugtriebwerke: grundlagen, aero-thermodynamik, ideale und reale kreisprozesse, thermische turbomaschinen, komponenten, emissionen und systeme, 4th edn. In: VDI-Buch. Springer Vieweg, Berlin, Germany (2015)

11. Seddon, J., Goldsmith, E.L.: Intake aerodynamics, 2nd edn. American Institute of Aeronautics and Astronautics, Reston, Va (1999)

12. Luidens, R.W., Stockman, N.O., Diedrich, J.H.: An Approach to Optimum Subsonic Inlet Design. ASME, New York, NY (1979)

13. Pierluissi, A., Smith, C., Bevis, D.: Intake lip design system for gas turbine engines for subsonic applications. In: 49th AIAA Aerospace Sciences Meeting, Orlando, Florida. American Institute of Aeronautics and Astronautics, Reston, Virigina (2011). https://doi.org/10.2514/6.2011-1130

14. Albert, M., Bestle, D.: Aerodynamic design optimization ofnacelle and intake. In: Aircraft Engine; Coal, Biomass and Alternative Fuels; Cycle Innovations. ASME Turbo Expo 2013: Turbine Technical Conference and Exposition, San Antonio, Texas, USA, Monday 3 June 2013, V002T01A014, vol. 2. ASME (2013). https://doi.org/10.1115/GT2013-94857

15. Albert, M., Bestle, D.: Automatic design evaluation of nacelle geometry using 3D-CFD. In: 15th AIAA/ISSMO Multidisciplinary Analysis and Optimization Conference, Atlanta, GA. American Institute of Aeronautics and Astronautics, Reston, Virginia (2014). https://doi.org/10.2514/6.2014-2039

16. Kazula, S., Wöllner, M., Höschler, K.: Identification of efficient geometries for variable pitot inlets for supersonic transport. AEAT 92(7), 981-992 (2020). https://doi.org/10.1108/ AEAT-11-2019-0228

17. Baier, H.: Morphelle - project final report. Morphing enabling technologies for propulsion system nacelles (2015). http://cordis. 
europa.eu/docs/results/341/341509/final1-morphelle_final_ report.pdf Accessed 25 Mar 2020

18. da Rocha-Schmidt, L., Hermanutz, A., Baier, H.: Progress towards adaptive aircraft engine nacelles. In: Proceedings of the 29th Congress of the International Council of the Aeronautical Sciences (2014)

19. Hermanutz, A., da Rocha-Schmidt, L., Baier, H.: Technology investigation of morphing inlet lip concepts for flight propulsion nacelles. EUCASS (2015)

20. Ozdemir, N.G., Scarpa, F., Craciun, M., Remillat, C., Lira, C., Jagessur, Y., Da Rocha-Schmidt, L.: Morphing nacelle inlet lip with pneumatic actuators and a flexible nano composite sandwich panel. Smart Mater. Struct. 24(12), 125018 (2015). https://doi. org/10.1088/0964-1726/24/12/125018

21. Kondor, S., Moore, M.: Experimental investigation of a morphing nacelle ducted fan. In: Proceedings of the 2004 NASA/ ONR Circulation Control Workshop, Part 1 (2004)

22. Kondor, S.: Further experimental investigations of circulation control morphing shrouded fan. In: 43rd AIAA Aerospace Sciences Meeting (2005)

23. Readnour, J.L., Wright, J.D.: Variable contour annular air inlet for an aircraft engine nacelle. Patent, US5000399 A (1991)

24. Sargisson, D.F.: Variable area inlet for a gas turbine engine. Patent, US4075833 A (1978)

25. SAE Aerospace: ARP4754A. Guidelines for Development of Civil Aircraft and Systems. SAE International, Warrendale, PA, United States (2010)

26. European Aviation Safety Agency: CS-25. Certification Specifications and Acceptable Means of Compliance for Large Aeroplanes, Amendment 18 (2016)

27. Verein Deutscher Ingenieure: VDI 2221 Blatt 1. Methodik zum Entwickeln und Konstruieren technischer Systeme und Produkte. Beuth Verlag GmbH, Berlin (2019)

28. Kazula, S., Höschler, K.: A systems engineering approach to variable intakes for civil aviation. In: Proceedings of the Institution of Mechanical Engineers, Part G. J. Aerosp. Eng. 234(10), 1721-1729 (2020). https://doi.org/10.1177/09544 10019836903

29. Kazula, S., Grasselt, D., Mischke, M., Höschler, K.: Preliminary safety assessment of circular variable nacelle inlet concepts for aero engines in civil aviation. In: Haugen, S., Barros, A., van Gulijk, C., Kongsvik, T., Vinnem, J.E. (eds.) Safety and reliability - safe societies in a changing world. Proceedings of the 28th International European Safety and Reliability Conference (ESREL 2018), Trondheim, Norway, 17-21 June 2018. A Balkema book, pp. 2459-2467. CRC Press, Taylor et Francis Group, Boca Raton, London, New York, Leiden (2018)

30. Kazula, S., Grasselt, D., Höschler, K.: Common Cause Analysis of Circular Variable Nacelle Inlet Concepts for Aero Engines in Civil Aviation. In: Silva Gomes, J.F., Meguid, S.A. (eds.) IRF2018. Proceedings of the 6th International Conference on Integrity-Reliability-Failure: (Lisbon/Portugal, 22-26 July 2018). FEUP-INEGI, Porto (2018)

31. Kazula, S., Höschler, K.: Ice detection and protection systems for circular variable nacelle inlet concepts. CEAS Aeronaut J 11(1), 229-248 (2020). https://doi.org/10.1007/ s13272-019-00413-1

32. Kazula, S., Rich, B., Höschler, K., Woll, R.: Awakening the Interest of high school pupils in science, technology, engineering and mathematics studies and careers through scientific projects. In: 2018 IEEE International Conference on Teaching, Assessment, and Learning for Engineering (TALE). IEEE International Conference on Teaching, Assessment, and Learning for Engineering (TALE), Wollongong, NSW, 04.12.2018 - 07.12.2018, pp. 259265. IEEE (2018). https://doi.org/10.1109/TALE.2018.8615418
33. Kazula, S., Höschler, K.: A variable pitot-inlet concept for supersonic aviation. In: Proceedings of Global Power \& Propulsion Society (2020). https://doi.org/10.33737/gpps20-tc-49

34. Rossow, C.-C., Wolf, K., Horst, P.: Handbuch der luftfahrzeugtechnik: mit 34 tabellen. Hanser, München (2014)

35. Oates, G.C. (ed.): Aircraft propulsion systems technology and design. AIAA education series, American Institute of Aeronautics and Astronautics, Washington, DC (1989)

36. Farokhi, S.: Aircraft propulsion. Wiley, Chichester, West Sussex, United Kingdom (2014)

37. Berens, T.: Aerodynamic propulsion integration for supersonic business jets. In: 46th AIAA/ASME/SAE/ASEE Joint Propulsion Conference \& Exhibit. 46th AIAA/ASME/SAE/ASEE Joint Propulsion Conference \& Exhibit, Nashville, TN. American Institute of Aeronautics and Astronautics, Reston, Virigina (2010). https:// doi.org/10.2514/6.2010-6591

38. Cousins, W.T.: History, Philosophy, physics, and future directions of aircraft propulsion system/inlet integration. In: Proceedings of the ASME Turbo Expo 2004. Presented at the 2004 ASME Turbo Expo, June 14-17, 2004, Vienna, Austria, pp. 305-320. ASME, New York, NY (2004). https://doi.org/10.1115/GT2004-54210

39. Dorsey, A.M., Hoffman, D.C., Palacios, F.D., Hoisington, Z.C.: Rotating devices for mitigation of adverse flow conditions in ultra-short nacelle inlet. Patent, EP3421373A1 (2019)

40. Hoisington, Z.C., Palacios, F.D., Hoffman, D.C., Dorsey, A.M., Sequeira, K.J., Frazier, R.C., Chapel, S.E.: Translating turning vanes for a nacelle inlet. Patent, US10436112B2 (2019)

41. Dilligan, M.A., Calkins, F.T., Zimmermann, T.J., Mabe, J.H., Blohowiak, K.Y.: Shape memory alloy actuator system for composite aircraft structures. patent, US 20160229519 A1 (2016)

42. Filter, E.J.: Variable geometry inlet for a ducted fan and method of assembling same. Patent, US 9297333 B2 (2016)

43. Huynh, T., Wilson, D.J.: Variable-capture supersonic inlet. Patent, US 20160288917 A1 (2016)

44. Labrecque, M., Couture-Gagnon, V., Ullyott, R.: Variable geometry inlet system. Patent, US20160053683 A1 (2016)

45. Rawdon, B.K., Harber, B.A., Harrison, N.A.: Dual-rib morphing leading edge. Patent, US 9415856 B2 (2016)

46. Gordon, J., Borgstrom, C., Fisher, N., Fuhrmeister, C., Madigan, N., Parkins, C.: Morphing wing leading edge. Patent, US8925870 B1 (2015)

47. Madsen, C.L.: Shape memory alloy rods for actuation of continuous surfaces. Patent, US 20150129715 A1 (2015)

48. Horwarth, N.: Air intake and a method of controlling the same. Patent, US 20140311580 A1 (2014)

49. Huynh, T.: Variable-geometry rotating spiral cone engine inlet compression system and method. Patent, US8690097 B1 (2014)

50. Jain, A.K., Winter, M.: Variable contraction ratio nacelle assembly for a gas turbine engine. Patent, EP1992810B1 (2014)

51. Jain, A.K., Winter, M.: Variable contraction ratio nacelle assembly for a gas turbine engine. Patent, US20080283676 A1 (2008)

52. Kosheleff, P.A.: Mass flow increase at takeoff in supersonic airliner. Patent, US8622339 B2 (2014)

53. Morford, S.A., Larkin, M.J.: Gas turbine engine having slim-line nacelle. Patent, US8726632 B2 (2014)

54. Surply, T., Bourdeau, C.: Turbojet nacelle and method for controlling separation in a turbojet nacelle. Patent, US8640986 B2 (2014)

55. Jain, A.K., Chaudhry, Z.A.: Variable shape inlet section for a nacelle assembly of a gas turbine engine. Patent, US 8402739 B2 (2013)

56. Jain, A.K., Winter, M.: Nacelle assembly having inlet airfoil for a gas turbine engine. Patent, US 8408491 B2 (2013)

57. Jain, A.K.: Nacelle flow assembly. Patent, US8596573 B2 (2013)

58. Shammoh, Ali A.A.J.: Adjustable angle inlet for turbojet engines. Patent, US 8544793 B1 (2013) 
59. Smith, A.R., Arzoglou, D.: Gas turbine engine nacelle (having a symmetric flowpath). Patent, US20100019100A1 (2013)

60. Vos, R., Barret, R.M.: Method and apparatus for pressure adaptive morphing structure. Patent, US8366057 B2 (2013)

61. Winter, M.: Fan nacelle flow control. Patent, US8529188 B2 (2013)

62. Wood, J.H., Dunne, J.P.: Morphing structure (and method). Patent, US8397485 B2 (2013)

63. Bulman, M.J., Billig, F.S.: Integrated air inlet system for multipropulsion aircraft engines. Patent, USRE43731 (2012)

64. Haas, M.: Nacelle assembly having inlet bleed. Patent, US8192147 B2 (2012)

65. Jain, A.K.: Nacelle flow assembly. Patent, US8282037B2 (2012)

66. Jain, A.K., Winter, M.: Variable geometry nacelle assembly for a gas turbine engine. Patent, US8205430B2 (2012)

67. Jain, A.K., Winter, M.: Gondelanordnung mit Einlassprofil für ein Gasturbinentriebwerk. Patent, EP 1988266 A2 (2008)

68. Quackenbuch, T.R., McKillip, R.M., Danilov, P.V.: Supersonic engine inlet diffuser with deployable vortex generators. Patent, US20120325325 A1 (2012)

69. Rainos, E.A., Allmon, B.L., Loewe, J.G., Brooks, W.C., Blanton, L.A., Tudor, C.J., Budinger, V.S.: Ice shed reduction for leading edge structures. Patent, US20120312924 A1 (2012)

70. Wood, J.H., Dunne, J.P.: Shape changing airfoil system. Patent, US8256719 B2 (2012)

71. Goossen, E., Cox, P.A., ÓBrien, P.: Morphing ducted fan for vertical take-off and landing vehicle. Patent, US20110147533 A1 (2011)

72. Winter, M., Kain, A.K.: Gas turbine engine system providing simulated boundary layer thickness increase. Patent, US8209953 B2 (2011). https://doi.org/10.1007/s13272-021-00520-y

73. Bolender, L., Wagnon, S.: Engine intake flap for being arranged on the housing of an air intake of an aircraft engine, as well as engine with such an engine intake flap and aircraft system. Patent, US20100307442A1 (2010)

74. Heintze, O., Kintscher, M., Lorkowski, T., Monner, H.P., Riemenschneider, J.: Aerodynamisches bauteil mit verformbarer außenhaut. Patent, DE 102009026457 A1 (2010)

75. Kosing, O., Schmidt-Eisenlohr, U.: Luftatmende gondel mit integriertem turbolader. Patent, DE102008027275 A1 (2010)

76. Haas, M.: Nacelle assembly with turbulators. Patent, US8186942 B2 (2009)

77. Hurwitz, W., Ochs, S.S.: Active flow control for nacelle inlet. Patent, US9157368 B2 (2009)

78. Jain, A.K., Winter, M.: Turbomachine with variable contour nacelle assembly and corresponding operating method. Patent, EP2011987 A2 (2009)

79. Mcdonough, M.P., Brown, K.T., Gilzean, S.: Aircraft engine nacelle with translating inlet cowl. Patent, EP 2199204 A2 (2009)

80. Winter, M.: Systems and methods for altering inlet airflow of gas turbine engines. Patent, US20090092482A1 (2009)

81. Zysman, S.H., Lord, W.K., Miller, R.M., Atassi, O.V.: Passive bondary layer bleed system for nacelle inlet airflow control. Patent, US 20090301095 A1 (2009)

82. Chaudhry, Z.A.: Nacelle with articulating leading edge slates. Patent, US20080308684 A1 (2008)

83. Jain, A.K.: Variable geometry gas turbine engine nacelle assembly with nanoelectromechanical system. Patent, US20080310956 A1 (2008)

84. Kobayashi, H., Tanatsugu, N., Sato, T., Kojima, T., Maru, Y.: Air intake and method for breathing air using an air intake. Patent, US7322179 B2 (2008)

85. Wood, J.H.: Shape changing structure. Patent, US 20060124801 A1 (2006)
86. Bagnall, A.M.: Variable position intake for an aircraft mounted gas turbine engine. Patent, US6945494 B2 (2005)

87. Sakurai, S., Fox, S., Grimlund, K.: Apparatus and methods for varying inlet lip geometry of a jet engine inlet. Patent, US20050022866A1 (2005)

88. Sanders, B.W., Koncsek, J.L., Hedges, L.S.: Supersonic externalcompression diffuser and method for designing same. Patent, US6793175 B1 (2004)

89. Sankrithi, M.M.K.V., Nelson, P.E.: Rotatable scarf inlet for an aircraft engine and method of using the same. Patent, US6764043 B2 (2004)

90. Dunne, J.P., Pitt, D.M., Kilian, K.J., White, E.V.: Apparatus for variation of a wall skin. Patent, US6588709 B1 (2003)

91. Gupta, A., Graziosi, P., Mani, R.: System and method for actively changing an effective flow-through area of an inlet region of an aircraft engine. Patent, US6655632 B1 (2003)

92. Sanders, B.W., Weir, L.J.: Low sonic boom inlet for supersonic aircraft. Patent, US7048229 B2 (2002)

93. Gruensfelder, C.A., Wille, R.H.: Mission adaptive inlet. Patent, US6231006 B1 (2001)

94. Bargadi, T.P., Jourdain, G.E.A.: System for the admission of air into a working section of a gas turbine engine. Patent, US6082669 A (2000)

95. Chevalier, A., Bouchez, M.: Variable geometry ramjet for aircraft. Patent, US5894722 A (1999)

96. Kutschenreuter, P.H., JR.: Telescoping centerbody wedge for a supersonic inlet. Patent, US5301901 A (1994)

97. Patilla, R.G.: Engine nacelle. Patent, US5145126 A (1992)

98. Perry, A.F.: Variable air intake. Patent, US 5116001 A (1992)

99. Tracksdorf, P.: Jet engine nacelle. Patent, US4865268 A (1989)

100. Lewis, W.J., Woodward, C.S.: Variable area aircraft air intake. Patent, US4782657 A (1988)

101. Haas, J.T., Hadwin, R.-L.: Controllable diffuser for an air intake of an aircraft. Patent, US4641678 A (1987)

102. Karanian, A.J.: Variable-geometry inlet. Patent, US4620679 A (1986)

103. Boulton, D.G., Arcengeli, G.T.: Vented cowl variable geometry inlet for aircraft. Patent, US4477039 A (1984)

104. McKinney, M.E., Rudolph, P.K.: Variable camber leading edge mechanism with Krüger flap. Patent, US4427168 A (1984)

105. Statkus, F.D.: Continuous skin, variable camber airfoil edge actuating mechanism. Patent, US4351502 A (1982)

106. Frantz, J.J.: Variable double lip quiet inlet. Patent, US4132240 A (1979). https://doi.org/10.1007/s13272-021-00520-y

107. Ball, W.H., Ishimitsu, K.K.: Variable camber inlet for supersonic aircraft. Patent, US4012013 (1977)

108. Demetrick, R.W.: Translating multi-ring inlet for gas turbine engines. Patent, US 3908683 (1975)

109. Sargisson, D.F.: Variable air inlet system for a gas turbine engine. Patent, US3915413 A (1975)

110. Dupcak, J., Traksel, J.: Air inlet flap. Patent, US3770228 A (1973)

111. Wilde, L.G., Rodgers, L.J.: Air intake for a gas turbine engine. Patent, US 3763874 A (1973)

112. Skidmore, W.E., Syltebo, B.E., Viall, W.S.: Aircraft engine variable highlight inlet. Patent, US 3664612 A (1972)

113. Poucher, M.: Air intakes for gas turbine engines. Patent, US3623494 A (1971)

114. Gero, O.: Variable profile air inlet lip for an aircraft engine. Patent, US3532305 A (1970)

115. Brown, D.: Air intake duct for a gas turbine engine. Patent, US3485252 A (1969)

116. Moorehead, J.R.: Fixed spike inlet with variable throat and capture area. Patent, US3242671 A (1966)

117. Wodehouse, A., Vasantha, G., Corney, J., Maclachlan, R., Jagadeesan, A.: The generation of problem-focussed patent 
clusters: a comparative analysis of crowd intelligence with algorithmic and expert approaches. Des. Sci. 3 (2017). https://doi. org/10.1017/dsj.2017.19

118. Niu, M.C.-Y.: Airframe structural design: practical design information and data on aircraft structures, 2nd edn. Conmilit Press, Hong Kong (2002)

119. Monner, H., Kintscher, M., Lorkowski, T., Storm, S.: Design of a smart droop nose as leading edge high lift system for transportation aircrafts. In: 50th AIAA/ASME/ASCE/AHS/ASC Structures, Structural Dynamics, and Materials Conference, Palm Springs, California. American Institute of Aeronautics and Astronautics, p. 3. Reston, Virigina (2009). https://doi.org/10. 2514/6.2009-2128

120. Kintscher, M., Wiedemann, M.: Investigation of multi-material laminates for smart droop nose devices. ICAS (2014)

121. Vasista, S., Mierheim, O., Kintscher, M.: Morphing structures, applications of. In: Altenbach, H., Öchsner, A. (eds.) Encyclopedia of Continuum Mechanics, pp. 1-13. Springer, Berlin, Heidelberg (2019)

122. Rudenko, A., Hannig, A., Monner, H.P., Horst, P.: Extremely deformable morphing leading edge: optimization, design and structural testing. J. Intell. Mater. Syst. Struct. 29(5), 764-773 (2018). https://doi.org/10.1177/1045389X17721036

123. El-Sayed, A.F.: Fundamentals of aircraft and rocket propulsion, p. 1010. Springer, London (2016)

124. Dunne, J.P., Hopkins, M.A., Baumann, E.W., Pitt, D.M., White, E.V.: Overview of the SAMPSON smart inlet. In: Jacobs, J.H. (ed.) Smart structures and materials 1999, pp. 380-390. Industrial and commercial applications of smart structures technologies, Newport Beach, CA (1999). https://doi.org/10.1117/12. 351575

125. Pitt, D., Dunne, J., White, E., Garcia, E.: SAMPSON smart inlet SMA powered adaptive lip design and static test. In: 19th AIAA Applied Aerodynamics Conference, Anaheim, CA, USA, 11 June 2001-14 June 2001, p. 1. American Institute of Aeronautics and Astronautics, Reston, Virigina (2001). https://doi.org/10.2514/6. 2001-1359

126. Pitt, D.M., Dunne, J.P., White, E.V., Garcia, E.: Wind tunnel demonstration of the SAMPSON Smart Inlet. In: McGowan, A.-M.R. (ed.) SPIE's 8th Annual International Symposium on
Smart Structures and Materials, Newport Beach, CA, Sunday 4 March 2001, pp. 345-356. SPIE (2001). https://doi.org/10.1117/ 12.429674

127. Pitt, D.M., Dunne, J.P., White, E.V.: SAMPSON smart inlet design overview and wind tunnel test: II Wind tunnel test. In: McGowan, A.- M.R. (ed.) PIE's 9th Annual International Symposium on Smart Structures and Materials, San Diego, CA, Sunday 17 March 2002, pp. 24-36. SPIE (2002). https://doi.org/10. $1117 / 12.475073$

128. Pitt, D.M., Dunne, J.P., White, E.V.: SAMPSON smart inlet design overview and wind tunnel test: I. Design overview Smart Structures and Materials, Industrial and Commercial Applications of Smart Structures Technologies, San Diego, CA, 13-23 (2002)

129. Aircraft Owners and Pilots Association: Sukhoi SU-29. Russian Rush (1992). https://www.aopa.org/news-and-media/allnews/ 1992/november/pilot/sukhoi-su-29

130. Greenblatt, D., Wygnanski, I.J., Rumsey, C.L.: Aerodynamic Flow Control. In: Blockley, R., Shyy, W. (eds.) Encyclopedia of aerospace engineering, vol. 42, p. 2205. Wiley Interscience, Hoboken, NJ (2010)

131. Lord, W., MacMartin, D., Tillman, G.: Flow control opportunities in gas turbine engines. In: Fluids 2000 Conference and Exhibit. Fluids 2000 Conference and Exhibit, Denver, CO, USA, 19 June 2000-22 June 2000. American Institute of Aeronautics and Astronautics, Reston, Virigina (2000)

132. Hamstra, J.W., McCallum, B.N.: Tactical Aircraft Aerodynamic Integration. In: Blockley, R., Shyy, W. (eds.) Encyclopedia of aerospace engineering, vol. 104, p. 473. Wiley Interscience, Hoboken, NJ (2010)

133. Joslin, R.D.: Overview of Laminar Flow Control. NASA/ TP-1998-208705. NASA Lewis Research Center, Hampton, VA United States (1998)

Publisher's Note Springer Nature remains neutral with regard to jurisdictional claims in published maps and institutional affiliations. 